\title{
Data concordance between ESRD Medical Evidence Report and Medicare Claims: is there any improvement?
}

\author{
Yi Mu ${ }^{1}$, Andrew I Chin ${ }^{2,3}$, Abhijit V Kshirsagar ${ }^{4}$, Heejung Bang ${ }^{\text {Corresp. 5, } 6}$ \\ ${ }^{1}$ Office of Population Health and Accountable Care, UCSF Medical Center, University of California, San Francisco, San Francisco, CALIFORNIA, United \\ States \\ 2 Division of Nephrology, University of California, Davis School of Medicine, University of California, Davis, Sacramento, CALIFORNIA, United States \\ 3 Division of Nephrology, Sacramento VA Medical Center, VA Northern California Health Care Systems, Mather Field, CALIFORNIA, United States \\ 4 UNC Kidney Center and Division of Nephrology and Hypertension, University of North Carolina at Chapel Hill, Chapel Hill, North Carolina, United States \\ 5 Division of Biostatistics, Department of Public Health Sciences, University of California, Davis, Davis, CALIFORNIA, United States \\ ${ }^{6}$ Center for Healthcare Policy and Research, Davis School of Medicine, University of California, Davis, Sacramento, CALIFORNIA, United States \\ Corresponding Author: Heejung Bang \\ Email address: hbang@ucdavis.edu
}

Background. Medicare is one of the world's largest health insurance programs. It provides health insurance to nearly 44 million beneficiaries whose entitlements are based on age, disability, or end-stage renal disease (ESRD). Data of these ESRD beneficiaries are collected in the US Renal Data System (USRDS), which includes comorbidity information entered at the time of dialysis initiation (Medical Evidence data), and are used to shape health care policy. One limitation of USRDS data is the lack of validation of these Medical Evidence comorbidities against other comorbidity data sources, such as medical claims data. Methods. We examined the potential for discordance between USRDS Medical Evidence and medical claims data for 11 comorbid conditions amongst Medicare beneficiaries in 2011-2013 via sensitivity, specificity, kappa and hierarchical logistic regression. Results. Among 61,280 patients, most comorbid conditions recorded on the Medical Evidence forms showed high specificity ( $>0.9$ ), compared to prior medical claims as reference standard. However, both sensitivity and kappa statistics varied greatly and tended to be low (most<0.5). Only diabetes appeared accurate, whereas tobacco use and drug dependence showed the poorest quality (sensitivity and kappa<0.1).

Institutionalization and patient region of residency were associated with data discordance for 6 and 5 comorbidities out of 11, respectively, after conservative adjustment of multiple testing. Discordance appeared to be non-informative for congestive heart failure but was most varied for drug dependence. Conclusions. We conclude that there is no improvement in comorbidity data quality in incident ESRD patients over the last two decades. Since these data are used in case-mix adjustment for outcome and quality of care metrics, the findings in this study should press regulators to implement measures to improve the accuracy of comorbidity data collection. 
2 Data Concordance between ESRD Medical Evidence Report and Medicare 3 Claims: is there any improvement?

4 Yi Mu PhD ${ }^{1}$, Andrew I. Chin MD²,3, Abhijit V. Kshirsagar MD, MPH ${ }^{4}$, Heejung Bang $\mathrm{PhD}^{5,6}$ 5

61 Office of Population Health and Accountable Care, UCSF Medical Center,

7 University of California, San Francisco, San Francisco, CALIFORNIA, United States 8

2 Division of Nephrology, University of California, Davis School of Medicine, University of California, Davis, Sacramento, CALIFORNIA, United States

3 Division of Nephrology, Sacramento VA Medical Center, VA Northern California Health Care Systems, Mather Field, CALIFORNIA, United States

4 UNC Kidney Center and Division of Nephrology and Hypertension, University of North Carolina at Chapel Hill, Chapel Hill, North Carolina, United States

5 Division of Biostatistics, Department of Public Health Sciences, University of California, Davis, Davis, CALIFORNIA, United States

6 Center for Healthcare Policy and Research, Davis School of Medicine, University of California, Davis, Sacramento, CALIFORNIA, United States

Running title: Comorbidities in ESRD

Article type: Original Investigation

Word count: Abstract 278, Manuscript 3401

Number of Tables and Figures: 3 Tables, 1 Figure

Supplemental files: Tables S1 and S2

Corresponding Author:

$\mathrm{Yi} \mathrm{Mu}, \mathrm{PhD}$

UCSF Health | Office of Population Health and Accountable Care 3360 Geary Blvd, Suite 201, Box 1819

San Francisco, CA 94143, USA.

Email: yi.mu@ucsf.edu

Tel: (415)-353-3107 


\section{Additional Information and Declarations}

\section{Human Ethics}

42 The University of California's Institutional Review Board (IRB) has determined that studies

43 using USRDS data do not constitute human subject research. Find our sample IRB determination 44 letter and data use agreement in Supplemental files.

\section{Data Availability}

46 Sample statistical programs (e.g., in SAS) can be provided upon request from the first author. 47 Data can not be publically shared due to our data use agreement with the data providers. We 48 obtained the data from the US Renal Data System via the National Institute of Diabetes and 49 Digestive and Kidney Diseases (NIDDK) by completing, submitting and following the standard 50 data use agreement. Interested readers should contact the Program Director at the NIDDK (e.g., 51 Dr. Keven Abbott currently) and use https:/www.usrds.org/request.aspx.

\section{Acknowledgements}

53 We thank Dr. Lorien Dalrymple for her early contribution to the conception of the work. 


\section{Abstract}

55 Background. Medicare is one of the world's largest health insurance programs. It provides health insurance to nearly 44 million beneficiaries whose entitlements are based on age,

57 disability, or end-stage renal disease (ESRD). Data of these ESRD beneficiaries are collected in 58 the US Renal Data System (USRDS), which includes comorbidity information entered at the time of dialysis initiation (Medical Evidence data), and are used to shape health care policy. One limitation of USRDS data is the lack of validation of these Medical Evidence comorbidities against other comorbidity data sources, such as medical claims data.

Methods. We examined the potential for discordance between USRDS Medical Evidence and medical claims data for 11 comorbid conditions amongst Medicare beneficiaries in 2011-2013 via sensitivity, specificity, kappa and hierarchical logistic regression.

Results. Among 61,280 patients, most comorbid conditions recorded on the Medical Evidence forms showed high specificity $(>0.9)$, compared to prior medical claims as reference standard. However, both sensitivity and kappa statistics varied greatly and tended to be low $(\operatorname{mos}<<0.5)$. Only diabetes appeared accurate, whereas tobacco use and drug dependence showed the poorest quality (sensitivity and kappa $<0.1$ ). Institutionalization and patient region of residency were associated with data discordance for 6 and 5 comorbidities out of 11, respectively, after conservative adjustment of multiple testing. Discordance appeared to be non-informative for congestive heart failure but was most varied for drug dependence.

Conclusions. We conclude that there is no improvement in comorbidity data quality in incident ESRD patients over the last two decades. Since these data are used in case-mix adjustment for outcome and quality of care metrics, the findings in this study should press regulators to implement measures to improve the accuracy of comorbidity data collection. 


\section{Introduction}

The United States Renal Data System (USRDS) is a national data system that includes extensive information about chronic kidney disease and end-stage renal disease (ESRD) in the US (USRDS 2016). In addition to patient-level data, USRDS also includes specifics of the dialysis clinics in which patients initiate dialysis. In the US, dialysis clinic oversight is divided amongst 18 networks that represent geographic regions of the country. Although the main strengths of the USRDS are its size and representativeness, its limitations include lack of validated comorbidity information and lack of complete laboratory data at initiation of renal replacement therapy (Foley \& Collins 2013).

The USRDS provides two major data sources for ascertaining comorbid conditions in patients on dialysis that are being used in current health care policy research and practice. One source is medical claims data and the other is medical evidence data (Medical Evidence Record Form, designated as CMS-2728 by Medicare), a single form completed by health care providers or staff exclusively at the time of dialysis initiation, a critical transition period in a patient's life, and providing baseline data upon patient entry into the ESRD program. Although the concise comorbidity data from CMS-2728 are easy to access, there has been ongoing concern about the reliability of CMS-2728 (Byrne \& Vernon 1991; Kim et al. 2012; Krishnan et al. 2015; Longenecker et al. 2000; Solid et al. 2014).

An important use of comorbidity data in health policy is in case-mix adjustment in the development of quality metrics of individual dialysis clinics, which are used to profile health care providers and facilities (Ash et al. 2012). Medicare administers the ESRD Quality Incentive Program (QIP) to promote high quality services in dialysis facilities treating outpatients with ESRD. ESRD-QIP in 2017 included standardized readmission ratio (SRR) as a clinical measure (CMS 2016; CMS 2017c). CMS also developed the Dialysis Facility Compare, a 5-Star Rating system of dialysis facilities for public reporting, which initially included a Standardized Mortality Ratio (SMR) and Standardized Hospitalization Ratio (SHR). SMR and SHR use CMS2728, while the SRR is calculated using past year claims for each index hospital discharge to adjust comorbidities (CMS 2014a; CMS 2017a; Kshirsagar et al. 2017; UM-KECC 2017).

Differences in health care delivery based on local and regional factors, items beyond patient or provider control, are also topics that have been highlighted over the last several years (Bernheim et al. 2016; Kshirsagar et al. 2017; Manickam et al. 2017; Martsolf et al. 2016a; 
109 Martsolf et al. 2016b). For example, regional differences have been associated with outcomes in

110 the ESRD setting, particularly when the West coast is compared against other regions of the US

111 (Almachraki et al. 2016; Kshirsagar et al. 2017; Mu et al. 2018), despite near universal care and

112 coverage offered in the US for ESRD.

113 Building upon the prior studies, we estimated and compared the prevalence and

114 concordance of 11 common comorbid conditions recorded on CMS-2728 versus those

115 determined by medical claims (Aim 1). We implemented different methods of claims data

116 processing in recognition that different algorithms are currently being used in different medical

117 conditions - for example, ESRD vs. cancer - and that substantial discordance has been reported

118 in claims even within a 1 year period in a given dialysis patient cohort (Krishnan et al. 2015). We

119 also examined if associations with regions and other external factors (we call 'environment-

120 related factors') were found in comorbidity ascertainment between CMS-2728 and medical

121 claims data (Aim 2); if no association is found, we can perhaps be more comfortable in the

122 accuracy of these data (Solid et al. 2014). Through these analyses, we intended to study if there

123 has been any improvement in comorbidity ascertainment data quality since 2010 .

124

125 Materials and Methods

\section{Study design and data sources}

127 Our study required comorbidity data prior to and at the time of ESRD. Therefore, we chose to 128 examine subjects who had Medicare parts A and B coverage and medical claims information 129 prior to ESRD. Since Medicare eligibility begins at age 65, we looked at those who started 130 dialysis at age $\geq 67$ years of age, allowing for at least one year of claims data prior to ESRD, 131 though this age restriction cannot guarantee the completeness of the past 2 years of Medicare 132 claims data.

133 Specifically, we included Medicare-eligible patients in the USRDS $\geq 67$ years of age at 134 the time of dialysis initiation, who were also enrolled in Medicare prior to ESRD, and who 135 started hemodialysis between January 1, 2011 and June 30, 2013. Additional inclusion criteria 136 included subjects who had a completed CMS-2728 form and had Medicare parts A and B as 137 primary payer 1 year prior to and at time of dialysis initiation. The final study cohort included 138 61,280 patients; see Figure 1. To ensure Medicare enrollment, we linked the USRDS to pre- 
139

140

141

142

143

144

145

146

147

148

149

150

151

152

153

154

155

156

157

158

159

160

161

162

163

164

165

166

167

168

169

ESRD Medicare claims data. We next linked the USRDS to the Dartmouth Atlas of Health Care and the American Community Survey to provide environment-related variables.

\section{Comorbidity and ascertainment algorithms}

We included 11 comorbid conditions found on the CMS-2728 form: atherosclerotic heart disease (AHD), congestive heart failure (CHF), cerebrovascular disease (CBVD), peripheral vascular disease (PVD), other cardiac diseases, chronic obstructive pulmonary disease (COPD), cancer, diabetes mellitus (DM), alcohol dependence, drug dependence, and tobacco use. To ascertain comorbid conditions using past-year Medicare claims, we considered the following 3 methods for data processing:

- Method A: We required at least one claim from an inpatient/home health agency/skilled nursing facility/hospice or at least two claims from an outpatient/physician-supplier.

- Method B: We required at least two claims from outpatient/physician-supplier more than 30 days apart, in addition to the criteria in Method A.

- Method C: We excluded co-existing radiology, diagnostic laboratory, and durable medical equipment physician-supplier. We then applied Method A.

Method A may be considered the current norm found in nephrology health care research (Krishnan et al. 2015), while Methods B and C were informed by cancer research, such as the Surveillance, Epidemiology, and End Results (SEER) program - using the SEER-Medicare dataset (Baldwin et al. 2006). We considered different processing methods because substantial discordance was found between claims ascertained before and shortly after dialysis initiation in a prior study on this subject matter (Krishnan et al. 2015).

\section{Environment-related factors}

We considered the external, regional and geographic factors as potentially influencing the outcome, data discordance (Almachraki et al. 2016; Kshirsagar et al. 2017; Mu et al. 2018). Specifically, we considered the following 7 factors: 1) patient's institutionalization status; 2) health care utilization intensity in patient's residence; 3) dialysis clinic size (patient volume); 4) geographic location/region of the country of the dialysis facility; 5) dialysis facility's rural-urban commuting area (RUCA); 6) regional poverty level; and 7) regional education level. As the study by Krishnan et al. had centered upon patient-level factors (e.g., demographics) (Krishnan et al. 
170 2015), we decided to include these facility/area-level factors. The institutionalization status of

171 patients was defined as nursing home, assisted living, or other. Dialysis facility geographic

172 location was assigned to 1 of 4 regions (Northeast, South, Midwest and West), which was

173 determined by the network in which the clinic resided (Dalrymple et al. 2014; Kshirsagar et al.

174 2017). Dialysis facility volume reflected the number of patients receiving hemodialysis in a year.

175 To assign dialysis facilities to a rural or urban area, we used ZIP code level RUCA (RUCA

176 2007) and ZIP code tabulation area (ZCTA) through the Uniform Data System Mapper

177 (http://udsmapper.org/zcta-crosswalk.cfm), then linked it to the 2010-2014 American

178 Community Survey (https:/www.census.gov/programs-surveys/acs/). We selected two regional

179 socio-economic indicators, both at the ZCTA level: percent of population below the federally

180 defined poverty line, and percent of population amongst persons aged $\geq 25$ years who have at

181 least a high school education (Manickam et al. 2017). We linked the USRDS to the 2011-2013

182 Dartmouth Atlas of Health Care (http://www.dartmouthatlas.org), and selected a measure of

183 intensity of health care utilization - reimbursements per decedent for inpatient hospitalizations

184 during the last six months of life - and matched it to the patient's state of residence and year of

185 dialysis initiation (Song et al. 2010).

187 Statistical analysis

188 Descriptive statistics were used to describe cohort characteristics and comorbidity prevalence.

189 For example, standard diagnostic statistics (Sensitivity (SN), specificity (SP)) and concordance

190 statistic (kappa) were computed to assess the agreement of the two data sources for each

191 comorbid condition, along with McNemar's test for correlated data; a larger value close to 1 is

192 interpreted as higher agreement for SN, SP and kappa although kappa can be low for a variable

193 with low prevalence despite high agreement (Byrt et al. 1993). We chose $>0.5$ as an ad-hoc

194 threshold for acceptability. We intentionally did not attempt to assess accuracy because neither

195 data source can be considered as gold standard. To examine factors that are associated with the

196 outcome (discordance $=0 / 1$ for No/Yes) using Method B, we implemented a hierarchical logistic

197 regression model with facility as random intercept and multi-variable adjustment (listed in Table

198 1) (Fitzmaurice et al. 2011). We computed conditional odds ratio (OR) along with 95\%

199 confidence interval (CI) and p-value, where a larger value of OR above 1 indicates more 
200 discordance and a lower value of OR below 1 indicates less discordance, equivalently, more 201 concordance.

202 As education level and poverty level tend to be correlated, we conducted sensitivity

203

204

205

206

207

208

209

210

211

212

213

214

215

216

217

218

219

220

221

222

223

224

225

226

227

228

229 analyses with either education or poverty, not both in the model, to handle the collinearity issue. In order to handle the multiple testing issue, we indicated $p<0.0001$, in addition to $p<0.05$, where we used $\mathrm{p}<0.0001$ as a conservative threshold for the summarization of the results and assessing statistical significance. All analyses were conducted using SAS $^{\circledR}$ version 9.4 (SAS Institute, Cary, NC, USA).

\section{Results}

\section{Cohort characteristics}

Our analyses included 61,280 patients from 5,588 dialysis facilities who initiated in-center hemodialysis during the period of 2011-2013 and who were also Medicare beneficiaries during the year prior to dialysis initiation; see Figure 1 for inclusion/exclusion criteria. Table 1 summarizes the study cohort regarding patient- and facility/area-level characteristics. About $60 \%$ of patients were 75 years old or older. About $75 \%$ of patients were White, $19 \%$ were Black, and $8 \%$ of patients identified as Hispanic. The most common primary causes of renal failure were diabetes (41\%) and hypertension (38\%).

\section{Comorbidities: prevalence, sensitivity, specificity, and kappa}

We compared the prevalence of 11 comorbidities and the agreement of data (presence vs. absence of comorbidity) between CMS-2728 and Medicare claims, where claims were processed by the three different methods described earlier; see Table 2. We used claims data as the reference standard in all comparisons. Among comorbid conditions, the category 'other cardiac diseases' was largely affected by which particular method was used to process the claim (41.8, $32.3,26.8 \%$ with methods A, B, C, respectively). In general, prevalence of comorbidities based on CMS-2728 was uniformly lower than that based on claims data. This discordance was especially notable for some conditions (i.e., AHD, COPD, CBVD, PVD, alcohol dependence, drug dependence, and tobacco usage) where prevalence estimates on the CMS-2728 form were less than half of that which was determined by claims. 
Overall specificity was high; most comorbidities showed specificity $>0.9$, except for

231

232

233

234

235

236

237

238

239

240

241

242

243

244

245

246

247

248

249

250

251

252

253

254

255

256

257

258

259

260

AHD (0.86-0.85), CHF (0.79-0.84), and other cardiac diseases (0.77-0.78). However, sensitivity varied dramatically across comorbid conditions, ranging from 0.04 to 0.86 . The comorbidity of DM had the highest sensitivity (SN 0.83-0.86), a lower but acceptable value for CHF (SN 0.570.59 ) and all other conditions showing $\mathrm{SN}<0.5$. The lowest sensitivity was observed for tobacco use and drug dependence $(\mathrm{SN}<0.1)$. The corresponding kappa statistics between the two data sources also varied markedly, ranging from 0.07 to 0.73 . Once again, the lowest agreement (kappa $\leq 0.1$ ) was observed in drug dependence and tobacco use. DM showed the highest agreement ( $\sim 0.72)$, while all other conditions showed $<0.5$.

In terms of the three methods for claims data processing, Methods $\mathrm{B}$ and $\mathrm{C}$ tended to yield lower prevalence of each comorbidity, but a slightly higher sensitivity with specificity virtually unchanged, compared to Method A.

\section{Factors associated with discordance between CMS-2728 and claims}

Table 3 presents ORs along with 95\% CIs for each factor and discordance for 10 comorbidities, where alcohol dependence was excluded due to non-convergent model fit. Institutionalization and geographic region were significantly associated with data discordance for the largest number of the comorbidities we examined; an institutionalized patient status was associated with discordance for 6 comorbidities (i.e., AHD, CBVD, other cardiac, PVD, COPD, drug dependence) with $\mathrm{OR}=1.1-2.3$, with $\mathrm{p}<0.0001$. Geographic region of patient residence was associated with 5 comorbidities (i.e., AHD, CBVD, other cardiac, PVD, tobacco use) with $\mathrm{OR}=0.5-1.3$. In contrast, other factors such as regional indicator of health care utilization, volume/size of the dialysis facility, urbanicity and regional socio-economic indicators (poverty and education levels) did not show systematic associations. Also, discordance appears to be noninformative for $\mathrm{CHF}(\mathrm{OR}=0.9-1.1$ with all $\mathrm{p}>0.05)$, which may imply good reliability in this variable. In comparison, discordance was most varied for drug dependence $(\mathrm{OR}=0.5-2.3)$.

Finally, our sensitivity analyses that intended to address collinearity between education and poverty showed very similar results and no impact on the key findings reported above, e.g., regarding institutionalization, regions and CHF. Results are summarized in Table_S.

\section{Discussion}


261 Administrative databases are increasingly used in research, public policy and even in informing

262 health care consumers, as in the case of the Dialysis Facility Compare program. In our study, we 263 utilized two major sources of comorbidity data in nephrology research and health policy in the

264 US - the Medical Evidence report (CMS-2728) that is completed once at the time of dialysis 265 initiation and Medicare claims.

266 Prior studies on differences in comorbidity ascertainment methodology in ESRD patients

267 have demonstrated a high degree of discordance and overall poor sensitivity, similar to what we

268 found in our study. Longnecker et al. used clinical chart data to validate comorbid conditions

269 reported on CMS-2728 in 1,005 patients who started dialysis from 1995 through 1998. The

270 average sensitivity was 0.59 and specificity was above 0.9 , with HIV showing the highest

271 accuracy (Longenecker et al. 2000). Krishnan et al. examined comorbidities recorded on CMS-

2722728 and claims before and after dialysis initiation based on 45,357 Medicare-enrolled patients

273 who initiated dialysis between 2007 and 2009. Excluding DM, the kappa statistic for measuring

274 data concordance (between claims before dialysis initiation vs. CMS-2728 at dialysis initiation,

275 and between claims before vs. after dialysis initiation) ranged from 0.05 to 0.58 . They also found

276 that patient demographics and the USRDS network in which the patient received dialysis were

277 associated with data discordance, but did not study specific dialysis facility or regional

278 characteristics, factors that we included in our analysis (Krishnan et al. 2015). On the other hand,

279 Solid et al. used Medicare outpatient dialysis claims to validate vascular access - a variable

280 newly added in the 2005 revision of the CMS-2728 form - among patients starting hemodialysis

281 in 2010 . The two sources agreed for $94 \%$ of 9,777 patients with a kappa statistic of 0.83 (Solid et

282 al. 2014). Cause of renal failure and predialysis nephrology care were also evaluated using

283 different data sources over different time periods; the former was reasonably accurate, not the

284 latter (Byrne \& Vernon 1991; Kim et al. 2012).

285 The two main goals of our study were 1) to check if there is a meaningful improvement in 286 quality of comorbidity data in the modern era of the many quality-based initiatives, compared to 287 that noted in prior studies; and 2) to identify environment-related (e.g., living condition, socio288 economic, dialysis facility or regional area) factors associated with data disagreement. An 289 ancillary goal was to examine different methods of claims data processing, although comorbidity 290 ascertainment algorithm using claims is relatively well established for research purposes, as 291 adapted from the SEER method and Charlson comorbidity index. 
292

293

294

295

296

297

298

299

300

301

302

303

304

305

306

307

308

309

310

311

312

313

314

315

316

317

318

319

320

321

322

Our findings relating to the first goal do not demonstrate a meaningful improvement in data quality. We found similar degrees of poor data discordance and sensitivity between CMS2728 and medical claims as were noted in prior studies, even in a more contemporary era where the stakes are higher for health care providers of ESRD patients to record accurate comorbidity data. Previous studies reported low kappa and sensitivity, and substantial under-reporting in CMS-2728, and our data did not show that these values have improved over time (Krishnan et al. 2015; Longenecker et al. 2000). In particular, our study can be directly compared with that by Krishnan et al. with these two studies adopting very similar inclusion and exclusions criteria, using different years of the USRDS. In contrast, we utilized a more contemporary cohort, examined 3 different methods of claims data processing (including the method of Krishnan et al.), employed multiple statistical measures (beyond kappa statistic), and used a better suited statistical model (accounting for clustering). As anticipated, the two cohorts showed a similar distribution of patient characteristics and similar kappa values. Medicare has tried on their part to improve comorbidity entry by health care providers. As a part of the national effort, CMS provides education and outreach for "Provider Compliance Program" (CMS 2014b).

Regarding the second goal, we newly identified that institutionalization (vs. communitydwelling) and some regions showed a higher frequency of misreporting comorbidity data than others. Midwestern, Northeastern and Southern regions tended to show more data discordance, compared to the Western region in most comorbidities except for drug dependence. Notably, the phenomenon of "West vs. others" in the context of ESRD care has been observed in prior studies with different outcomes (Kshirsagar et al. 2017; Mu et al. 2018). This regional variation may have policy implications because near universal care and coverage are uniquely available for ESRD by Medicare in the US. Medicare regulators charged with developing future quality metrics that are, in part, based on comorbidities may need to consider these additional regional variations in monitoring comorbidity data reliability. As a model example provided by the investigators from the USRDS data center, 'vascular access type' used for dialysis that is being used for payment (since 2010) successfully passed the data reliability test based on high values in the proportion of agreement as well as kappa statistic, coupled with the absence of statistically significant predictors (among demographics) for disagreement (Solid et al. 2014).

We used 3 different but related methods of claims data processing. While we did not necessarily find one method to be overall superior to the others, we believe that Method A is 
323

324

325

326

327

328

329

330

331

332

333

334

335

336

337

338

339

340

341

342

343

344

345

346

347

348

349

350

351

352

353

easiest and most inclusive and Method C may be most restrictive (Baldwin et al. 2006; Krishnan et al. 2015). It is our opinion that investigator assumptions and preferences, and possibly the particular variable involved, may dictate the method that future investigators choose. We feel that including the 3 methods in our study might provide some guidance on these decisions. CMS currently established the Medicare and Medicaid Electronic Health Record (EHR) Incentive Programs to encourage health care providers and institutions to adopt, implement, upgrade, and demonstrate meaningful use of certified EHR technology (CMS 2017b). Hopefully with this and advanced medical informatics and algorithms (Hehner et al. 2017), comorbidity data capture can be more complete and accurate. Indeed, since the time of this study, Medicare has begun using prevalent comorbidities to the SMR and SHR calculations (CMS 2017d).

Our study has several limitations. First, the findings are limited to elderly in-center hemodialysis patients with Medicare as primary payer prior to dialysis initiation; thus, generalizability to other populations may be limited. Second, neither data source used can serve as a gold standard; thus, we could not assess true data accuracy. Claims data are generally regarded as more accurately recorded, so we used it as the reference standard. Indeed, Krishnan et al. proposed the use of claims during the 3 months after dialysis initiation as a useful source of comorbidity data (Krishnan et al. 2015). In our study, kappa (for concordance) and sensitivity (for diagnostics) yielded qualitatively similar results. Third, we did not investigate how certain factors, especially those that are not included in the current profiling model and quality metrics being used by CMS, such as prior nephrology care and geographic region, impact on the profiling status, which is warranted in future research (Liu et al. 2016).

\section{Conclusion}

Our study raises continued concern about the highly varied data quality in comorbidity information amongst patients with ESRD in the US. Although we used a more recent cohort, we conclude that no improvement was observed over the last two decades, and our results emphasize the concerns about the data accuracy of the comorbidities on the CMS-2728 form and its associated use in developing health policies. Hopefully, these studies provide further incentive to improve data accuracy, identify more reliable data sources and raise awareness of potential bias. 
354

355

356

357

358

359

360

361

362

363

364

365

366

367

368

369

370

371

372

373

374

375

376

377

378

379

380

381

382

383

384

385

386

387

388

389

390

391

392

393

394

395

396

397

398

399

400

\section{References}

Almachraki F, Tuffli M, Lee P, Desmarais M, Shih H-C, Nissenson AR, and Krishnan M. 2016. Socioeconomic status of countries where dialysis clinics are located is an important factor in comparing dialysis providers. Population Health Management 19:70-76.

Ash AS, Fienberg SF, Louis TA, Normand SLT, Stukel TA, and Utts J. 2012. Statistical issues in assessing hospital performance. https://wwwcmsgov/Medicare/Quality-Initiatives-Patient-AssessmentInstruments/HospitalQualityInits/Downloads/Statistical-Issues-in-Assessing-HospitalPerformancepdf last access Oct 2017.

Baldwin L, Klabunde C, Green P, Barlow W, and Wright G. 2006. In search of the perfect comorbidity measure for use with administrative claims data: does it exist? Medical Care 44:745-753.

Bernheim SM, Parzynski CS, Horwitz L, Lin Z, Araas MJ, Ross JS, Drye EE, Suter LG, Normand S-LT, and Krumholz HM. 2016. Accounting for patients' socioeconomic status does not change hospital readmission rates. Health Affairs 35:1461-1470.

Byrne C, and Vernon P. 1991. Validation of the cause of renal failure of patients in the Medicare endstage renal disease program. American Journal of Kidney Diseases 18:375-378.

Byrt T, Bishop J, and Carlin JB. 1993. Bias, prevalence and kappa. Journal of Clinical Epidemiology 46:423429.

CMS. 2014a. Centers for Medicare \& Medicaid Services. ESRD QIP Summary: Payment Years $2014-2018$ https://www.cms.gov/Medicare/Quality-Initiatives-Patient-AssessmentInstruments/ESRDQIP/Downloads/ESRDQIPSummaryPaymentYears2014-2018.pdf last access Febuary 2017.

CMS. 2014b. https://www.cms.gov/Outreach-and-Education/Medicare-Learning-NetworkMLN/MLNEdWebGuide/Downloads/MLN-Compliance-Webinar.pdf last accessed April 2018.

CMS. 2016. https://www.cms.gov/Medicare/Quality-Initiatives-Patient-AssessmentInstruments/ESRDQIP/Downloads/ESRD-QIP-Summary-Payment-Years-2016-\%E2\%80\%932020.pdf last access April 2018.

CMS. 2017a. Centers for Medicare \& Medicaid Services. Dialysis Facility Compare. https://www.medicare.gov/dialysisfacilitycompare/\#data/about-data last access Febuary 2017.

CMS. 2017b. Centers for Medicare \& Medicaid Services. Electronic Health Records (EHR) Incentive Programs https://www.cms.gov/Regulations-and-Guidance/Legislation/EHRIncentivePrograms/ last access February 2018.

CMS. 2017c. https://www.cms.gov/Medicare/Quality-Initiatives-Patient-AssessmentInstruments/ESRDQIP/Downloads/ESRDQIPPY2017finaltechnicalmeasurespecifications-.pdf last access April 2018.

CMS. 2017d. Report for the Standardized Hospitalization Ratio NQF \#1463. https://www.cms.gov/Medicare/Quality-Initiatives-Patient-AssessmentInstruments/ESRDQIP/Downloads/SHR-Methodology-Report June2017.pdf last access April 2018.

Dalrymple LS, Johansen KL, Romano PS, Chertow GM, Mu Y, Ishida JH, Grimes B, Kaysen GA, and Nguyen DV. 2014. Comparison of hospitalization rates among for-profit and nonprofit dialysis facilities. Clinical Journal of the American Society of Nephrology 9:73-81.

Fitzmaurice G, Laird N, and Ware J. 2011. Applied Longitudinal Analysis, 2nd edition: John Wiley \& Sons. Foley RN, and Collins AJ. 2013. The USRDS: what you need to know about what it can and can't tell us about ESRD. Clinical Journal of the American Society of Nephrology 8:845-851.

Hehner S, Kors B, Martin M, Uhrmann-Klingen E, and Waldron J. 2017. https://healthcare.mckinsey.com/sites/default/files/Artificial\%20intelligence\%20in\%20Health\% 20Insurance.pdf, last access April 2018.1-10. 
401

402

403

404

405

406

407

408

409

410

411

412

413

414

415

416

417

418

419

420

421

422

423

424

425

426

427

428

429

430

431

432

433

434

435

436

437

438

439

440
Kim J, Desai M, Chertow G, and Winkelmayer W. 2012. Validation of reported predialysis nephrology care of older patients initiating dialysis. Journal of the American Society of Nephrology 23:10781085.

Krishnan M, Weinhandl ED, Jackson S, Gilbertson DT, and Lacson E. 2015. Comorbidity ascertainment from the ESRD Medical Evidence Report and Medicare claims around dialysis initiation: a comparison using US Renal Data System data. American Journal of Kidney Diseases 66:802-812.

Kshirsagar AV, Manickam RN, Flythe JE, Chin Al, and Bang H. 2017. Area-level poverty, race/ethnicity \& dialysis star ratings. Plos One 12:e0186651.

Liu J, Krishnan M, Zhou J, Nieman KM, Peng Y, and Gilbertson DT. 2016. Data completeness as an unmeasured confounder in dialysis facility performance comparison with 1-year follow-up. Clinical Nephrology 86:262-269.

Longenecker JC, Coresh J, Klag MJ, Levey AS, Martin AA, Fink NE, and Powe NR. 2000. Validation of comorbid conditions on the end-stage renal disease medical evidence report: the CHOICE study. Journal of the American Society of Nephrology 11:520-539.

Manickam RN, Mu Y, Kshirsagar A, and Bang H. 2017. Area-level poverty and excess hospital readmission ratio. American Journal of Medicine 130:e153-155.

Martsolf GR, Barrett ML, Weiss AJ, Kandrack R, Washington R, Steiner CA, Mehrotra A, SooHoo NF, and Coffey RM. 2016a. Impact of race/ethnicity and socioeconomic status on risk-adjusted hospital readmission rates following hip and knee arthroplasty. J Bone Joint Surg Am 98:1385-1391.

Martsolf GR, Barrett ML, Weiss AJ, Washington R, Steiner CA, Mehrotra A, and Coffey RM. 2016b. Impact of race/ethnicity and socioeconomic status on risk-adjusted readmission rates: implications for the Hospital Readmissions Reduction Program. Inquiry 53:1-9.

Mu Y, Chin Al, Kshirsagar AV, Zhang Y, and Bang H. 2018. Regional and temporal variations in comorbidity among US dialysis patients: a longitudinal study of Medicare claims data. Inquiry 55:46958018771163. doi: $46958018771110.46958018771177 / 0046958018771163$.

RUCA. 2007. RUCA ZIP Version 2.0. http://depts.washington.edu/uwruca/ruca-download.php, last accessed Oct 2017.

Solid CA, Collins AJ, Ebben JP, Chen SC, Faravardeh A, Foley RN, and Ishani A. 2014. Agreement of reported vascular access on the medical evidence report and on medicare claims at hemodialysis initiation. BMC Nephrology 15:30.

Song Y, Skinner J, Bynum J, Sutherland J, Wennberg JE, and Fisher ES. 2010. Regional variations in diagnostic practices. New England Journal of Medicine 363:45-53.

UM-KECC. 2017. Technical Notes on the Standardized Mortality Ratio (SMR) for the Dialysis Facility Reports. https://dialysisdata.org/sites/default/files/content/Methodology/SMRDocumentation.pdf last access October 2017.

USRDS. 2016. US Renal Data System 2016 Annual Data Report: Atlas of Chronic Kidney Disease and EndStage Renal Disease in the United States. Bethesda, MD: National Institutes of Health, National Institute of Diabetes and Digestive and Kidney Diseases. 


\title{
Figure 1 (on next page)
}

\author{
Cohort selection
}




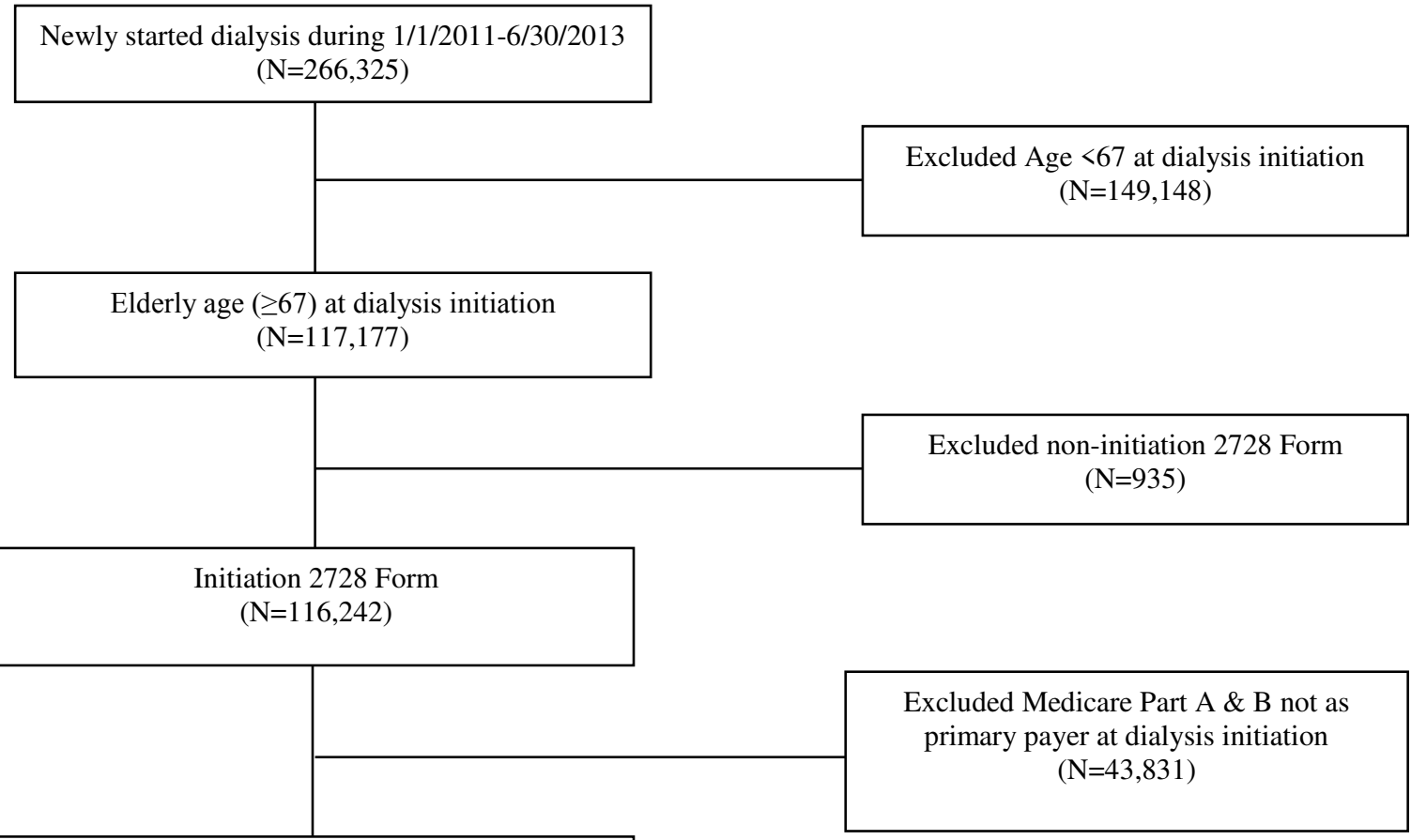

Medicare Part A \& B as primary payer at dialysis initiation $(\mathrm{N}=72,411)$

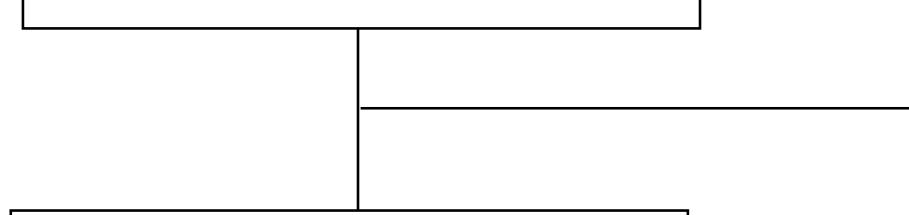

Excluded Medicare Part A \& B not as primary payer during one year prior to dialysis initiation $(\mathrm{N}=6,701)$

Medicare Part A \& B as primary payer during one year prior to dialysis initiation $(\mathrm{N}=65,710)$

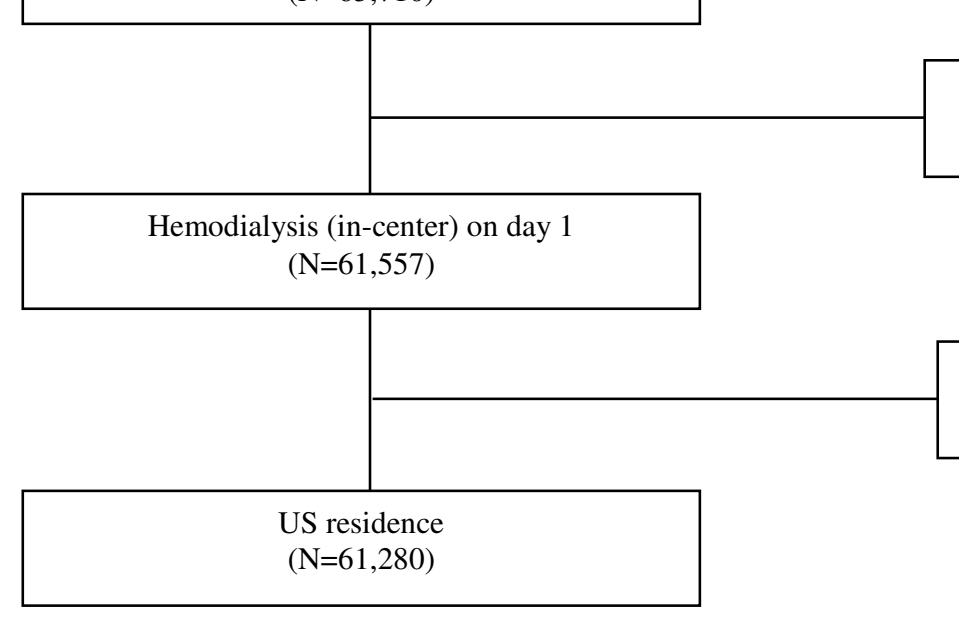

Excluded not in-center Hemodialysis on day $1(\mathrm{~N}=4,153)$

Excluded non-US residence $(\mathrm{N}=277)$ 
Table $\mathbf{1}$ (on next page)

Cohort characteristics $(N=61,280)$

None 
Table 1

Cohort characteristics $(\mathrm{N}=61,280)$

\begin{tabular}{|c|c|c|c|c|c|c|c|}
\hline Patient level & Category & $\mathbf{N}$ & $\%$ & Facility Level & Category & $\mathbf{N}$ & $\%$ \\
\hline \multirow[t]{3}{*}{ Age } & {$[67,75)$} & 24,336 & 39.7 & Number of & Missing & 899 & 1.5 \\
\hline & {$[75,85)$} & 27,616 & 45.1 & patients & $\leq 40$ & 10,000 & 16.3 \\
\hline & $\geq 85$ & 9328 & 15.2 & $\begin{array}{l}\text { per facility } \\
\text { (volume) }\end{array}$ & $41-63$ & 13,651 & 22.3 \\
\hline \multirow[t]{3}{*}{ Gender } & Female & 28,088 & 45.8 & & $64-91$ & 16,670 & 27.2 \\
\hline & Male & 33,190 & 54.2 & & $>91$ & 20,060 & 32.7 \\
\hline & Unknown & 2 & & Region & Missing & 583 & 1 \\
\hline \multirow[t]{3}{*}{ Race } & Black & 11,514 & 18.8 & & Northeast & 11,227 & 18.3 \\
\hline & White & 46,956 & 76.6 & & South & 23,857 & 38.9 \\
\hline & Other & 2,810 & 4.6 & & Midwest & 15,508 & 25.3 \\
\hline \multirow[t]{2}{*}{ Ethnicity } & Non-Hispanic & 56,417 & 92.1 & & West & 10,105 & 16.5 \\
\hline & Hispanic & 4,863 & 7.9 & RUCA & Missing & 750 & 1.2 \\
\hline Primary cause & Diabetes & 24,834 & 40.5 & & Urban & 47,649 & 77.8 \\
\hline \multirow[t]{3}{*}{ of ESRD } & Hypertension & 23,098 & 37.7 & & Large Rural & 8,865 & 14.5 \\
\hline & $\begin{array}{l}\text { Glomerulo- } \\
\text { nephritis }\end{array}$ & 2,806 & 4.6 & & Small Rural & 3,267 & 5.3 \\
\hline & Other & 10,542 & 17.2 & & $\begin{array}{l}\text { Isolated } \\
\text { Small Rural }\end{array}$ & 749 & 1.2 \\
\hline $\begin{array}{l}\text { Healthcare } \\
\text { Utilization* }\end{array}$ & 1 & 5,168 & 8.4 & All people & Missing & 719 & 1.2 \\
\hline \multirow[t]{3}{*}{ Quartile } & 2 & 11,456 & 18.7 & below poverty & $<5$ & 3,737 & 6.1 \\
\hline & 3 & 22,175 & 36.2 & in past 12 months, & $5-9.9$ & 12,048 & 19.7 \\
\hline & 4 & 22,481 & 36.7 & $\%$ & $10-14.9$ & 12,384 & 20.2 \\
\hline \multirow{2}{*}{$\begin{array}{l}\text { Institutionaliz } \\
\text { ation }\end{array}$} & No & 52,165 & 85.1 & & 15-19.9 & 12,407 & 20.3 \\
\hline & Yes & 9,115 & 14.9 & & $20-24.9$ & 8,964 & 14.6 \\
\hline \multirow{5}{*}{$\begin{array}{l}\text { Prior } \\
\text { nephrology } \\
\text { care }\end{array}$} & $<6$ months & 8,590 & 14 & & $\geq 25$ & 11,021 & 18 \\
\hline & 6-12 months & 10,569 & 17.3 & Adults $\geq 25 \mathrm{yr}$ & Missing & 627 & 1 \\
\hline & $>12$ months & 18,607 & 30.4 & who has Bachelor & $<20$ & 20,931 & 34.2 \\
\hline & No & 15,336 & 25 & or higher, & {$[20,30)$} & 17,410 & 28.4 \\
\hline & Unknown & 8,178 & 13.4 & $\%$ & $\geq 30$ & 22,312 & 36.4 \\
\hline
\end{tabular}

$2 *$ Healthcare utilization is defined as reimbursement per decedent for inpatient hospitalization during the 3 last 6 months at state level. 


\section{Table 2 (on next page)}

Prevalence and Agreement: Medical evidence (CMS-2728) vs. claims data $(N=61,280)$

* Method A, B, and C: see Method section. Sensitivity and Specificity were computed with claims data as reference standard.From McNemar's test $p<0.0001$, except for Other cardiac ( $p=0.60$ for Method C vs CMS2728). 
Table 2

Prevalence and Agreement: Medical evidence (CMS-2728) vs. claims data $(\mathrm{N}=61,280)$

\begin{tabular}{|c|c|c|c|c|c|c|}
\hline Comorbidity & \% (CMS-2728) & Method* & $\%$ (Claims) & Kappa & Sensitivity & Specificity \\
\hline \multirow[t]{3}{*}{ Diabetes mellitus } & \multirow[t]{3}{*}{57.3} & A & 64.8 & 0.71 & 0.83 & 0.91 \\
\hline & & $\mathrm{B}$ & 62.6 & 0.72 & 0.85 & 0.89 \\
\hline & & $\mathrm{C}$ & 61.8 & 0.73 & 0.86 & 0.89 \\
\hline \multirow[t]{3}{*}{ Cancer } & \multirow[t]{3}{*}{11.9} & A & 18.9 & 0.42 & 0.41 & 0.95 \\
\hline & & $\mathrm{B}$ & 15.6 & 0.42 & 0.44 & 0.94 \\
\hline & & $\mathrm{C}$ & 15.6 & 0.42 & 0.44 & 0.94 \\
\hline \multirow[t]{3}{*}{ Congestive heart failure } & \multirow[t]{3}{*}{41.1} & A & 60.7 & 0.38 & 0.57 & 0.84 \\
\hline & & $\mathrm{B}$ & 52.8 & 0.38 & 0.59 & 0.79 \\
\hline & & $\mathrm{C}$ & 56.0 & 0.39 & 0.59 & 0.82 \\
\hline \multirow{3}{*}{$\begin{array}{l}\text { Chronic obstructive } \\
\text { pulmonary disease }\end{array}$} & \multirow[t]{3}{*}{14.3} & A & 33.6 & 0.34 & 0.34 & 0.96 \\
\hline & & $\mathrm{B}$ & 30.1 & 0.36 & 0.36 & 0.95 \\
\hline & & $\mathrm{C}$ & 31.3 & 0.35 & 0.35 & 0.95 \\
\hline \multirow[t]{3}{*}{ Cerebrovascular disease } & \multirow[t]{3}{*}{11.6} & A & 23.0 & 0.24 & 0.27 & 0.93 \\
\hline & & $\mathrm{B}$ & 17.4 & 0.27 & 0.31 & 0.92 \\
\hline & & $\mathrm{C}$ & 17.9 & 0.27 & 0.31 & 0.93 \\
\hline \multirow[t]{3}{*}{ Atherosclerotic heart disease } & \multirow[t]{3}{*}{27.2} & A & 57.4 & 0.21 & 0.37 & 0.86 \\
\hline & & $\mathrm{B}$ & 52.5 & 0.22 & 0.38 & 0.85 \\
\hline & & $\mathrm{C}$ & 53.5 & 0.22 & 0.38 & 0.85 \\
\hline \multirow[t]{3}{*}{ Peripheral vascular disease } & \multirow[t]{3}{*}{16.3} & A & 39.2 & 0.19 & 0.27 & 0.9 \\
\hline & & $\mathrm{B}$ & 32.9 & 0.21 & 0.28 & 0.9 \\
\hline & & $\mathrm{C}$ & 33.9 & 0.21 & 0.28 & 0.9 \\
\hline \multirow[t]{3}{*}{ Alcohol dependence } & \multirow[t]{3}{*}{0.8} & A & 2.3 & 0.21 & 0.14 & 1 \\
\hline & & $\mathrm{B}$ & 2.0 & 0.2 & 0.15 & 1 \\
\hline & & $\mathrm{C}$ & 2.2 & 0.21 & 0.15 & 1 \\
\hline \multirow[t]{3}{*}{ Other cardiac } & \multirow[t]{3}{*}{26.9} & A & 41.8 & 0.13 & 0.34 & 0.78 \\
\hline & & $\mathrm{B}$ & 32.3 & 0.14 & 0.36 & 0.77 \\
\hline & & $\mathrm{C}$ & 26.8 & 0.14 & 0.37 & 0.77 \\
\hline \multirow[t]{3}{*}{ Tobacco use } & \multirow[t]{3}{*}{3.5} & A & 22.5 & 0.1 & 0.09 & 0.98 \\
\hline & & $\mathrm{B}$ & 21.4 & 0.1 & 0.09 & 0.98 \\
\hline & & $\mathrm{C}$ & 22.1 & 0.1 & 0.09 & 0.98 \\
\hline \multirow[t]{3}{*}{ Drug dependence } & \multirow[t]{3}{*}{0.1} & A & 1.0 & 0.07 & 0.04 & 1 \\
\hline & & $\mathrm{B}$ & 0.9 & 0.07 & 0.04 & 1 \\
\hline & & $\mathrm{C}$ & 0.9 & 0.07 & 0.04 & 1 \\
\hline
\end{tabular}

* Method A, B, and C: see Method section.

Sensitivity and Specificity were computed with claims data as reference standard.

From McNemar's test $\mathrm{p}<0.0001$, except for Other cardiac ( $\mathrm{p}=0.60$ for Method C vs CMS-2728). 


\section{Table 3 (on next page)}

Environment-related factors associated with discordance between CMS-2728 and past year claims data

Alcohol dependence was not included due to models not convergent.If $p<0.0001$, then bold; If $0.0001<p<0.05$, then italic, where $p$-values were unadjusted for multiple testing.AHD:atherosclerotic heart disease; $\mathrm{CHF}$ :congestive heart failure;

CBVD:cerebrovascular disease; PVD:peripheral vascular disease; COPD:chronic obstructive pulmonary disease;RUCA:rural-urban commuting area. 
1 Table 3 Environment-related factors associated with discordance between CMS-2728 and past 2 year claims data

3 a. Cardiovascular disease-related comorbidities

\begin{tabular}{|c|c|c|c|c|c|c|}
\hline & & & Odds ra & (95\% confid & e interval) & \\
\hline Factors & & AHD & CHF & CBVD & Other cardiac & PVD \\
\hline Institutionaliz & zation Yes vs. No & $1.1(1.1-1.2)$ & $1.1(1.0-1.1)$ & $1.4(1.3-1.5)$ & $1.2(1.2-1.3)$ & $1.3(1.3-1.4)$ \\
\hline Healthcare & 2 & $1.1(1.0-1.2)$ & $1.0(0.9-1.1)$ & $1.0(0.9-1.1)$ & $1.0(0.9-1.1)$ & $1.0(0.9-1.1)$ \\
\hline utilization & 3 & $1.2(1.1-1.3)$ & $1.0(1.0-1.1)$ & $1.0(0.9-1.1)$ & $1.0(1.0-1.1)$ & $1.1(1.0-1.2)$ \\
\hline quartile & 4 vs. 1 & $1.4(1.3-1.5)$ & $1.1(1.0-1.2)$ & $1.0(1.0-1.1)$ & $1.1(1.0-1.1)$ & $1.2(1.1-1.2)$ \\
\hline Volume & $41-63$ & $1.0(0.9-1.0)$ & $1.0(1.0-1.1)$ & $1.0(1.0-1.1)$ & $1.1(1.0-1.1)$ & $1.0(1.0-1.1)$ \\
\hline (no of patient & $64-91$ & $0.9(0.9-1.0)$ & $1.0(0.9-1.0)$ & $1.0(1.0-1.1)$ & $1.0(1.0-1.1)$ & $1.0(1.0-1.1)$ \\
\hline per facility) & $>91$ vs. $\leq 40$ & $0.9(0.9-1.0)$ & $1.0(1.0-1.1)$ & $1.0(0.9-1.1)$ & $1.0(1.0-1.1)$ & $1.0(1.0-1.1)$ \\
\hline Region & Midwest & $1.2(1.1-1.3)$ & $1.0(0.9-1.1)$ & $1.1(1.0-1.2)$ & $1.1(1.0-1.2)$ & $1.1(1.1-1.2)$ \\
\hline & Northeast & $1.0(1.0-1.1)$ & $1.0(0.9-1.1)$ & $1.1(1.0-1.2)$ & $1.2(1.1-1.2)$ & $1.3(1.2-1.4)$ \\
\hline & South vs. West & $1.3(1.2-1.4)$ & $1.1(1.0-1.1)$ & $1.2(1.1-1.3)$ & 1.1(1.1-1.2) & $1.0(1.0-1.1)$ \\
\hline RUCA & Large rural & $0.9(0.8-0.9)$ & $0.9(0.9-1.0)$ & $0.9(0.9-1.0)$ & $1.0(0.9-1.0)$ & $1.0(0.9-1.0)$ \\
\hline & Small rural & $0.9(0.8-1.0)$ & $0.9(0.8-1.0)$ & $0.9(0.8-1.0)$ & $1.0(0.9-1.0)$ & $0.9(0.8-1.0)$ \\
\hline Isolated & small rural vs. Urban & $0.8(0.7-0.9)$ & $1.0(0.9-1.2)$ & $1.0(0.8-1.2)$ & $1.1(1.0-1.3)$ & $1.1(0.9-1.3)$ \\
\hline People in & $<5$ & $1.1(1.0-1.3)$ & $0.9(0.8-1.0)$ & $1.1(1.0-1.3)$ & $1.2(1.1-1.3)$ & $1.1(1.0-1.2)$ \\
\hline poverty, $\%$ & $5-9.9$ & $1.0(1.0-1.1)$ & $1.0(0.9-1.0)$ & $1.1(1.0-1.2)$ & $1.1(1.0-1.2)$ & $1.0(1.0-1.1)$ \\
\hline & $10-14.9$ & $1.0(1.0-1.1)$ & $1.0(0.9-1.0)$ & $1.1(1.0-1.1)$ & $1.1(1.1-1.2)$ & $1.0(1.0-1.1)$ \\
\hline & $15-19.9$ & $1.0(0.9-1.0)$ & $1.0(0.9-1.0)$ & $1.1(1.0-1.1)$ & $1.1(1.1-1.2)$ & $1.0(0.9-1.1)$ \\
\hline & $20-24.9$ vs. $\geq 25$ & $1.0(1.0-1.1)$ & $1.0(1.0-1.1)$ & $1.0(1.0-1.2)$ & $1.1(1.0-1.1)$ & $1.0(1.0-1.1)$ \\
\hline Adults with & $20-29.9$ & $1.0(0.9-1.0)$ & $1.0(0.9-1.0)$ & $1.0(1.0-1.1)$ & $1.0(1.0-1.1)$ & $1.0(0.9-1.0)$ \\
\hline $\begin{array}{l}\geq \text { bachelor } \\
\text { degree , } \%\end{array}$ & $\geq 30$ vs. $<20$ & $0.9(0.8-0.9)$ & $1.0(0.9-1.0)$ & $0.9(0.9-1.0)$ & $1.0(0.9-1.0)$ & $0.9(0.9-1.0)$ \\
\hline
\end{tabular}

4 Alcohol dependence was not included due to models not convergent.

5 If $\mathrm{p}<0.0001$, then bold; If $0.0001<\mathrm{p}<0.05$, then italic, where $\mathrm{p}$-values were unadjusted for multiple testing.

6 AHD:atherosclerotic heart disease; CHF:congestive heart failure; CBVD:cerebrovascular disease; PVD:peripheral vascular disease;

7 RUCA:rural-urban commuting area. 
b. Non-cardiovascular disease-related comorbidities

\begin{tabular}{|c|c|c|c|c|c|c|}
\hline \multirow{2}{*}{\multicolumn{2}{|c|}{ Factors }} & \multicolumn{5}{|c|}{ Odds ratio ( $95 \%$ confidence interval) } \\
\hline & & COPD & Cancer & $\begin{array}{l}\text { Diabetes } \\
\text { mellitus }\end{array}$ & $\begin{array}{l}\text { Drug } \\
\text { dependence }\end{array}$ & Tobacco use \\
\hline \multicolumn{2}{|c|}{ Institutionalization Yes vs. No } & $1.2(1.2-1.3)$ & $0.9(0.9-1.0)$ & $1.1(1.0-1.1)$ & $2.3(2.1-2.6)$ & $1.1(1.0-1.1)$ \\
\hline \multicolumn{2}{|c|}{ Healthcare $\quad 2$} & $1.0(0.9-1.1)$ & $1.0(0.9-1.1)$ & $1.1(1.0-1.2)$ & $1.1(0.9-1.4)$ & $1.0(0.9-1.1)$ \\
\hline \multicolumn{2}{|l|}{ utilization } & $1.1(1.0-1.2)$ & $1.0(0.9-1.1)$ & $1.2(1.0-1.3)$ & $1.0(0.8-1.3)$ & $1.0(0.9-1.1)$ \\
\hline \multicolumn{2}{|l|}{ quartile } & $1.1(1.0-1.2)$ & $1.0(0.9-1.1)$ & 1.2(1.1-1.3) & $1.0(0.8-1.3)$ & $1.0(0.9-1.1)$ \\
\hline \multirow{3}{*}{$\begin{array}{l}\text { Volume } \\
\text { (no of patients } \\
\text { per facility) }\end{array}$} & $41-63$ & $1.0(0.9-1.0)$ & $1.0(0.9-1.1)$ & $1.0(0.9-1.0)$ & $0.7(0.5-0.8)$ & $1.0(0.9-1.1)$ \\
\hline & $64-91$ & $0.9(0.9-1.0)$ & $1.1(1.0-1.2)$ & $0.9(0.8-1.0)$ & $0.8(0.6-1.0)$ & $1.1(1.0-1.1)$ \\
\hline & $>91$ vs. $\leq 40$ & $0.9(0.9-1.0)$ & $1.0(0.9-1.1)$ & $1.0(0.9-1.1)$ & $0.8(0.7-1.1)$ & $1.0(0.9-1.0)$ \\
\hline \multirow[t]{3}{*}{ Region } & Midwest & $1.0(1.0-1.1)$ & $1.1(1.0-1.2)$ & $1.0(0.9-1.1)$ & $0.5(0.4-0.8)$ & $1.2(1.1-1.3)$ \\
\hline & Northeast & $1.0(1.0-1.1)$ & $1.1(1.0-1.2)$ & $1.2(1.1-1.3)$ & $0.6(0.4-0.8)$ & $1.1(1.0-1.2)$ \\
\hline & South vs. West & $1.0(1.0-1.1)$ & $1.1(1.0-1.2)$ & $1.1(1.0-1.2)$ & $0.7(0.5-0.9)$ & $1.0(0.9-1.1)$ \\
\hline \multirow[t]{2}{*}{ RUCA } & Large rural & $1.0(1.0-1.1)$ & $1.0(0.9-1.0)$ & $0.9(0.9-1.0)$ & $0.9(0.7-1.2)$ & $1.0(0.9-1.1)$ \\
\hline & Small rural & $1.0(0.9-1.1)$ & $0.9(0.8-1.0)$ & $0.8(0.7-0.9)$ & $0.4(0.3-0.7)$ & $0.9(0.8-1.0)$ \\
\hline \multicolumn{2}{|c|}{ Isolated small rural vs. Urban } & $1.0(0.8-1.2)$ & $1.0(0.8-1.2)$ & $0.8(0.6-1.0)$ & $1.6(0.8-3.3)$ & $1.1(0.9-1.4)$ \\
\hline \multirow{5}{*}{$\begin{array}{l}\text { People in } \\
\text { poverty, } \%\end{array}$} & $<5$ & $1.0(0.9-1.1)$ & $1.1(1.0-1.3)$ & $1.0(0.9-1.2)$ & $0.7(0.4-1.3)$ & $1.2(1.1-1.4)$ \\
\hline & $5-9.9$ & $1.0(1.0-1.1)$ & $1.1(1.0-1.2)$ & $0.9(0.8-1.0)$ & $0.6(0.5-0.9)$ & $1.2(1.1-1.3)$ \\
\hline & $10-14.9$ & $1.0(0.9-1.1)$ & $1.1(1.0-1.2)$ & $1.1(0.9-1.1)$ & $0.8(0.6-1.1)$ & $1.1(1.0-1.2)$ \\
\hline & $15-19.9$ & $1.0(0.9-1.1)$ & $1.1(1.0-1.2)$ & $1.0(0.9-1.1)$ & $0.8(0.6-1.1)$ & $1.1(1.0-1.2)$ \\
\hline & $20-24.9$ vs. $\geq 25$ & $1.0(0.9-1.1)$ & $1.1(1.0-1.2)$ & $1.1(1.0-1.2)$ & $1.0(0.7-1.3)$ & $1.1(1.0-1.2)$ \\
\hline \multirow{2}{*}{\multicolumn{2}{|c|}{$\begin{array}{lr}\text { Adults with } & 20-29.9 \\
\geq \text { bachelor } & \geq 30 \text { vs. }<20 \\
\text { degree , \% } & \\
\end{array}$}} & $1.0(0.9-1.0)$ & $1.0(0.9-1.1)$ & $0.9(0.9-1.0)$ & $1.3(1.0-1.7)$ & $1.0(0.9-1.1)$ \\
\hline & & $0.9(0.8-1.0)$ & $1.1(1.0-1.1)$ & $0.9(0.8-1.0)$ & $1.3(1.1-1.8)$ & $1.0(0.9-1.0)$ \\
\hline
\end{tabular}

11 If $\mathrm{p}<0.0001$, then bold; If $0.0001<\mathrm{p}<0.05$, then italic, where $\mathrm{p}$-values were unadjusted for multiple testing. 